Egyptian Poultry Science Journal

http://www.epsj.journals.ekb.eg/

ISSN: 1110-5623 (Print) - 2090-0570 (Online)

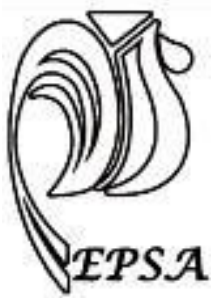

\title{
IMPACT OF PELLET BINDER ON BROILER PERFORMANCE AND FEED PROCESSING ECONOMICS
}

\author{
M.A.M. Abdelaziz \\ Poult. Prod. Dept., Fac. of Agric., Ain Shams Univ., Egypt \\ Corresponding author:Mrwan Abdelaziz; E-mail: mrwanabdelaziz@agr.asu.edu.eg
}

Received: 4/12/2020

Accepted: $22 / 12 / 2020$

\begin{abstract}
Total number of 216 one-day-old, unsexed Hubbard broiler chicks were used to study effects of pellet binder level together with pelleting diameter on growth performance, carcass measurements, and economic efficiency. Experimental birds were distributed over 6 groups, each group comprised of 36 chicks in 6 replicates of 6 chicks each. The experimental dietary treatments were as follows: control (T1) basal diet (BD) that is pelleted in standard diameter (SD) with addition of calcium lignosulfonate (CL) $2 \mathrm{Kg}$ / Ton; (T2) BD pelleted in SD with CL $4 \mathrm{Kg}$ / Ton; (T3) BD pelleted in SD with CL $8 \mathrm{Kg}$ / Ton; (T4) BD pelleted in a diameter thicker that SD by $1.0 \mathrm{~mm}$ (SD+1) with CL $2 \mathrm{Kg}$ / Ton; (T5) BD pelleted in SD+1 with CL $4 \mathrm{Kg}$ / Ton; and (T6) BD pelleted in SD+1 with CL $8 \mathrm{Kg} / \mathrm{Ton}$. Obtained results showed that all parameters of growth performance; live body weight (LBW), daily weight gain (DWG), daily feed consumption (DFC), and feed conversion ratio (FCR) were not significantly affected $(\mathrm{P}>0.05)$ by dietary treatments. Also, values of growth efficiency; relative growth rate (RGR), performance index (PI), production efficiency factor (PEF), protein conversion ratio (PCR), and energy conversion ratio (ECR) indicated no significant differences $(\mathrm{P}>0.05)$ within all tested groups. Moreover, data of carcass traits; dressed carcass, abdominal fat, giblets, total edible parts appeared significantly similar $(\mathrm{P}>0.05)$ among all treatments. Additionally, data of economic evaluation showed better economic efficiency with T2, T5, or T6 groups when compared to other groups. It could be concluded that using CL as a pellet binder in SD conditions, could be more beneficial with inclusion level of $4 \mathrm{Kg} / \mathrm{Ton}$. Moreover, it might be advised to include CL at $8 \mathrm{Kg}$ / Ton in diets only when pelleting feedatSD+1 as these conditions positively maintained performance and carcass of birds.
\end{abstract}

Key words: calcium lignosulfonate, broiler, pellet diameter, performance, carcass. 


\section{INTRODUCTION}

The pelleting process of feeds is a hydrothermal procedure in feed processing (Abdollahiet al., 2013).The benefits of pelleting feeds have been well documented with decreased feed wastage, reduced selective feeding, decreased ingredient segregation, less time and energy spent on prehension, and improved palatability (Moritz et al., 2002; Behnke and Beyer, 2002).Earlier research and investigations about pelleted feeds, have proven advantages that are associated with improved feed handling characteristics, increased feed consumption and body weight gain, and improved feed conversion ratio (Behnke, 1996; Jensenet al., 1962).In Addition, McKinney and Teeter (2004) revealed that pelleted feeds reduce energy required by birds that is actually spent on acquiring feed. And according to quality of pelleted feed, broilers that were fed hard pellets recorded improved nutrient retention and subsequent growth performance when compared with broilers fed soft pellets (Parsons et al., 2006). Theses authors also stated that pellet consistency might affect broilers in an approach like that of particle size of feed ingredients. One of well-known techniques that are used to resolve poor pellet quality is the utilization of pellet binders as most feed manufacturers use lignin, as lignosulphonate as feed pellet binder (Baurhooet al., 2008). Calcium lignosulfonate (CL) has been used in a wide range of industries, as lignosulfonates have specific dispersing, binding, and emulsifying properties (Cecilia et al., 2008). Due to the binding properties of CL, it is used as a pellet binder in feed processing to improve pellet quality (Acaret al., 1991). To exploit benefits of CL usage, feed must not only be pelleted simply, but it should be produced using specific techniques that maintain nutrient availability as inclusion of CL in pelleted feed reduced energy use of the pellet mill, pellet temperature after extrusion, and increased pellet quality (Corey et al., 2014).Furthermore, Abadi et al. (2019b) stated that diets containing $0.5 \% \mathrm{CL}$ had better physical pellet quality values. In general, most studies done for examining CL as a pellet binder mostly focus on absolute pellet quality rather than the effect of pelleting diameter. Accordingly, the present study aimed to investigate effects of using different levels of CL $(2,4$, or $8 \mathrm{Kg}$ / Ton) along with two different pelleting diameters [standard diameter (SD) or $1.0 \mathrm{~mm}$ thicker than standard diameter $(\mathrm{SD}+1)]$ of broiler feeds, on growth performance, carcass traits and economic features.

\section{MATERIALS AND METHODS}

\section{Birds and experimental diets}

A total number of two hundred sixteen unsexed one-day-old Hubbard broiler chicks were randomly distributed into 6 treatments. Each treatment comprised of 36 chicks which were divided into 6 replicates of 6 chicks each which were reared up to 33 days of age in wire-floored batteries. Three periodical diets were presented as starter diet (1 - 11 days); grower diet (12-22 days); and finisher diet (23 - 33 days). During each of these three phases, pelleted feed is presented in two diameters according to experimental design: standard diameter (SD) or standard diameter $+1 \mathrm{~mm}(\mathrm{SD}+1)$. Diameters of (SD) pelleted feeds were $1.5,2.5$, and $3.5 \mathrm{~mm}$ for starter, grower, and finisher diets, respectively. While diameters of $(\mathrm{SD}+1)$ pelleted feeds were $2.5,3.5$, and $4.5 \mathrm{~mm}$ for starter, grower, and finisher diets, respectively. Furthermore, the studied pellet binder material; Calcium lignosulfonate (CL) was added to diets in three levels. CL is a product of GREEN AGROCHEM CO., LTD, China. This pellet binder is designed to be added to finished feed mix by about 2 $\mathrm{Kg} / \mathrm{Ton}$. There were 6experimental diets; Control (T1) basal diet (BD) that is pelleted in SD with addition of CL $2 \mathrm{Kg} / \mathrm{Ton}$; (T2) $\mathrm{BD}$ pelleted in SD with CL $4 \mathrm{Kg}$ / Ton; (T3) 
BD pelleted in SD with CL $8 \mathrm{Kg} / \mathrm{Ton}$; (T4) $\mathrm{BD}$ pelleted in $\mathrm{SD}+1$ with CL $2 \mathrm{Kg} / \mathrm{Ton}$; (T5) BD pelleted in SD+1 with $\mathrm{CL} 4 \mathrm{Kg}$ / Ton; and (T6) BD pelleted in SD+1 with CL $8 \mathrm{Kg} /$ Ton. As shown in Table 1, diets used in the present study were formulated to ensure adequate supply of nutrients suggested by guidebook of Hubbard broilers according to NRC (1994). All birds were reared under similar management conditions, with feed and water being provided ad libitum.

\section{Growth performance}

Live body weight (LBW) of birds was recorded, and daily weight gain (DWG) was calculated per by subtracting the initial LBW from final LBW, then divided by number of rearing days. Daily feed consumption (DFC) was calculated from difference between amount of feed provided for each replicate and residual quantity, then divided by number of rearing days. Feed conversion ratio (FCR); $\mathrm{g}$ feed/ g gain; was calculated as the amount of feed consumed, in grams which is required to produce out one gram of weight gain. Relative growth rate (RGR), performance index (PI), and production efficiency factor (PEF) were calculated according to Brody (1945), North (1981), and Emmett (2000), respectively as follows:

$\mathrm{RGR}=\frac{\mathrm{w} 2-\mathrm{w} 1}{1 / 2(\mathrm{w} 1+\mathrm{w} 2)} \times 100$

w1: initial live weight, w2: final live weight

$\mathrm{PI}=\frac{\text { Live body weight }(\mathrm{Kg})}{\text { Feed Conversion Ratio }} \times 100$

$\mathrm{PEF}=\frac{\text { Livability } \times \text { Mass }(\mathrm{Kg})}{\mathrm{FCR} \times \text { Age in days }} \times 100$

Livability $=100-$ Mortality rate $(\%)$, Mass $(\mathrm{Kg})=$ Final live body weight.

\section{Carcass measurements}

At 33 days of age, six birds representing each treatment, were randomly taken, weighed, and slaughtered for carcass evaluation. After slaughter, birds were eviscerated and giblets (gizzard, liver, and heart) were separated from viscera and the gizzard was cut, open and cleaned. The dressed carcass, giblets, and abdominal fat were weighed and then expressed as a percentage of the live body weight.

\section{Economic values}

The economic characters were calculated according to prices of local market at the time of the study as follows:

Total $\cos t=$ feed cost + price of one-day-old chick + incidental expenses

Total return $=$ price of one $\mathrm{Kg}$ live weight $\times$ final LBW

Net return $=$ total return - total cost

Economic efficiency $=$ [net return / total cost $] \times 100$

\section{Statistical analysis}

All data were analyzed by one-way analysis of variance (ANOVA) followed by Duncan to compare the means between individual treatments using statistical analysis system (SAS, 2004) version 9.1 for Windows at $\mathrm{P}<0.01$ level and presented as mean values with \pm standard error of the mean (S.E.M, $r=3$ ). The data were subjected to statistical analysis according to the following model: $\mathrm{Y}_{\mathrm{ij}}=\mu+\mathrm{T}_{\mathrm{i}}+\mathrm{e}_{\mathrm{ij}}$ Where: $\mathrm{Y}_{\mathrm{ij}}=$ the experimental observation, $\mu=$ overall mean, $\mathrm{T}_{\mathrm{i}}=$ dietary treatment, $e_{i j}=$ experimental error. Then, individual effects of experimental groups were compared using Duncan (1955) multiple range tests at $\alpha$ level equal to 0.05 or 0.01 .

\section{RESULTS AND DISCUSSION}

\section{Growth performance:}

Effects of different dietary treatments on live body weight (LBW), daily weight gain (DWG), daily feed consumption (DFC) and feed conversion ratio (FCR) are presented in Table 2. Data shows that final LBW was not significantly affected by treatments. Similarly values of DWG (g/ day) were significantly similar $(\mathrm{P}>0.05)$ among all treatments. However, valuesof LBW and 
DWG recorded mathematically higher values with birds of T6 group. In the same way, data of DFC (g/ day) present insignificant differences within different test groups. Also, all groups appeared significantly similar regarding values of FCR ( $\mathrm{g}$ feed/ $\mathrm{g}$ gain). Though birds of T2grouprecorded numerically better FCR value when compared to other experimental groups. Results of current study agree with those of Abadi et al., (2019a), who stated that level of pellet binder of broiler feed had no significant effect on LBW and FCR up to 42 days of age. On the other hand, obtained results disagree with Corey et al. (2014) who stated that broilers fed diets pelleted with variant levels of CL, presented increment in feed consumption and body weight gain. However, Acaret al. (1991) found that broiler feed consumption was increased with using CL as pellet binder; with worsened FCR values. Although no significant differences, the numerical positive response on LBW of T6 group can be described as pellet size fits bird's oral cavity (Moran, 1989) and consequently less activity that is required throughout eating and resting activities (Skinner-Nobleet al., 2005). In the same way and according to earlier study, Cerrateet al. (2008) stated that thicker presenting thicker pellets to broilers during grower phase recoded higher feed consumption. Several previous studies are in accord with these results (Engberg et al., 2002; Maiorkaet al., 2005; Salariet al., 2006; Jahan et al., 2006)

\section{Growth efficiency:}

Table 3 presents data of relative growth rate (RGR), performance index (PI), production efficiency factor (PEF), protein conversion ratio (PCR), and energy conversion ratio(ECR) as affected by dietary treatments. The results indicated that all experimental groups recorded significantly similar $(P>0.05)$ values of RGR. Similarly values of PI appeared unaffected by any of test diets. However, the group of birds that were fed
T6 diet (SD+1 \& CL $8 \mathrm{Kg} /$ Ton) showed numerically better PI value. In the same way, PEF of the group fed T6 diet (SD+1 \& CL $8 \mathrm{Kg} /$ Ton) present mathematically higher value, though all groups appeared significantly similar. Regarding values of both PCR (g protein/g gain) or ECR (1000 Kcal/ g gain), all groups seemed significantly the same. These results are in a partial agreement with those of Abadi et al., (2019a), who reported that PEF of broilers at 42 days of age was not significantly affect by the level of pellet binder. Values representing RGR, PI or PEF had almost the same pattern as those of growth performance; LBW and FCR, as treatments higher body weight also recorded better growth efficiency values. Despite insignificance of tested parameters, improved body weight in relation to increased dietary nutrient density might be attributed to short time of feeding (Cerrateet al., 2008).

\section{Carcass traits:}

Data of percentile carcass traits as affected by experimental treatments are presented in Table 4. Values of dressed carcass were not significantly $(\mathrm{P}>0.05)$ affected by any of test diets. Also, abdominal fat values seemed significantly similar within all groups. Likewise, there were no significant variations among tested groups concerning percentages of giblets or total edible parts. It is widely known that feed particle size greatly affects gastrointestinal development specially the gizzard (Hetlandet al., 2002). Consequently, fine feed will lead to a poorly developed gizzard (Taylor and Jones, 2004), while large and tough particles improve gizzard muscles (Svihus, 2014). Despite pelleted feed might differ in diameter, all feed ingredients are ground finely prior to mixing and pelting which make pellet feed ineffective in gizzard development regardless the pellet diameter (Aguzeyet al., 2018). Results of the current study agreed 
with those of Glover et al. (2016) who stated that breast yield was not significantly affected by presenting either high- or lowquality pelleted feed for broilers. Also, carcass yield and abdominal fat percentages were not affected by neither feed form nor feed particle size (Mingbinet al., 2015).Moreover, abdominal fats remained rather unaffected by increased dietary nutrient density (Saleh et al., 2004). In accordance with earlier studies, Acaret al. (1991) stated that carcass yield of broilers was not affected by dietary inclusion of CL as pellet binder. On the other hand, Saleh $e t$ al. (2004) declared that higher nutrient density levels tended to decrease dressing percentage of broilers. While other study showed that abdominal fat percentage was increased with added CL in pelleted feeds for broilers (Acaret al., 1991).

\section{Economic efficiency:}

As shown in Table 5, under conditions of the present study, birds fed T1 (control), T3, or T5 diets presented lower economic efficiency(EE) values, when compared with other groups. As there was a clear decline in the net return for these groups in comparison with other treatments. On the other hand, birds fed $\mathrm{T} 2, \mathrm{~T} 4$, or $\mathrm{T} 6$ diets recorded better EE values as corresponding net return rates were higher when compared to that of other groups. Higher relative economic efficiency (REE) value recorded by $\mathrm{T} 2$ group $(+7.54 \%)$ is correlated to lower feed costs for this group, as birds recorded slightly lower value of DFC. Alternatively, better REE recorded for T4 and T6 groups $(+8.61 \%$ and $10.65 \%)$ was attributed to a clear increase in total return for these groups, as birds recorded marginally higher values of final LBW. Dietary treatments $\mathrm{T} 2$ or T6 include higher level of CL, being $4,8 \mathrm{Kg} / \mathrm{Ton}$, respectively. This inclusion level helped in reduction of energy use of the pellet mill which decrease pelleting costs and increase overall pellet quality (Corey et al., 2014).In general, economics of selection of dietary nutrient density should be taken into considerations prior to realization of improvement of production parameters (Saleh et al. (2004). It is widely known that feed costs are about $60-65 \%$ of the total cost of any broiler operation, therefore it is advisable to minimize manufacturing costs (Cutlipet al., 2008). Because the cost of feed is a substantial portion of producing meat, even small increases in feed conversion can increase economic returns as observed with data recorded with birds fed $\mathrm{T} 2$ diet (SD \& CL $2 \mathrm{Kg} /$ Ton).

\section{CONCLUSION}

It could be concluded that, pelleted feed for broilers at standard pelleting diameter(SD) could be economically utilized with the addition of CL at $4 \mathrm{Kg}$ / Ton. And to present more economical feed processing and utilization, it could be advised to add CL at 8 $\mathrm{Kg} / \mathrm{Ton}$ with pelleting feed with $1.0 \mathrm{~mm}$ thicker diameter $(\mathrm{SD}+1)$. This statement is realized after reviewing all obtained results which present no adverse effects of dietary treatments on all recorded data of performance and carcass.

\section{ACKNOWLEDGMENTS}

Author presents great thanks to Feed mixEgypt company, for presenting valuable technical advising and supporting the present trial with all required feeds. 
Table (1):Feed ingredients and chemical analyses of experimental basal diets.

\begin{tabular}{|l|c|c|c|}
\hline \multicolumn{1}{|c|}{ Ingredients } & Starter & Grower & Finisher \\
\hline Yellow Corn Grains & 58.03 & 61.69 & 65.55 \\
Soybean Meal & 35.05 & 27.00 & 19.70 \\
Full-fat Soybean & 3.39 & 8.30 & 11.85 \\
Calcium Carbonate & 1.21 & 1.12 & 1.03 \\
Mono-Calcium Phosphate & 0.91 & 0.57 & 0.51 \\
DL-Methionine & 0.30 & 0.25 & 0.26 \\
Vitamin-Mineral Premix* & 0.30 & 0.30 & 0.30 \\
Salt (NaCl) \& Sodium Sulphate & 0.40 & 0.40 & 0.40 \\
Lysine-HCl & 0.14 & 0.11 & 0.13 \\
L-Threonine & 0.06 & 0.05 & 0.06 \\
Additive Mix** & 0.21 & 0.21 & 100.00 \\
Total & 100.00 & 100.00 & 3100 \\
\hline \multicolumn{2}{|c|}{ Proximate Composition of Nutrients } & 18.50 \\
\hline Metabolizable Energy (KCal/Kg) & 2925 & 3015 & 0.70 \\
Crude Protein \% & 22.50 & 20.50 & 0.38 \\
Calcium \% & 0.90 & 0.80 & 1.10 \\
Available Phosphorus \% & 0.48 & 0.40 & 0.54 \\
Lysine \% & 1.35 & 1.21 & 0.87 \\
Methionine \% & 0.63 & 0.56 & 1.98 \\
Methionine + Cysteine \% & 1.01 & 0.92 & 3.5 \\
Threonine \% & 0.92 & 0.84 & \\
\hline \multicolumn{2}{|c|}{ Diameter of Feed Pellets(mm) } & 2.5 \\
\hline Standard diameter (SD) & 1.5 & 3.5 & \\
Standard diameter + 1 mm (SD+1) & 2.5 & & \\
\hline
\end{tabular}

* Vitamin-Mineral premix contains: Vitamins: A: 12000000 IU; D3 2000000 IU; E: 10000 mg; K3: 2000 mg; B1:1000 mg; B2: 5000 mg; B6:1500 mg; B12: 10 mg; Biotin: $50 \mathrm{mg}$; Choline chloride: $250000 \mathrm{mg}$; Pantothenic acid: $10000 \mathrm{mg}$; Nicotinic acid: $30000 \mathrm{mg}$; Folic acid: $1000 \mathrm{mg}$; Minerals: Mn: $60000 \mathrm{mg}$; Zn: $50000 \mathrm{mg}$; Fe: $30000 \mathrm{mg}$; Cu: $10000 \mathrm{mg}$; I: $1000 \mathrm{mg}$; Se: $100 \mathrm{mg}$ and Co: $100 \mathrm{mg}$. ** Additive Mix: Anti-toxin, Anti-coccidia

Table ( $r$ ):Effect of dietary treatments on growth performance (1-33 days of age).

\begin{tabular}{|c|c|c|c|c|c|c|c|}
\hline \multirow{2}{*}{ Parameters } & \multicolumn{7}{|c|}{ Dietary Treatments } \\
\hline & 1 & 2 & 3 & \begin{tabular}{|l|}
4 \\
\end{tabular} & 5 & 6 & Sig. \\
\hline Initial LBW* ${ }^{*}(\mathrm{~g})$ & $46.83 \pm 0.83$ & $48.12 \pm 0.95$ & $47.96 \pm 0.08$ & $49.16 \pm 1.10$ & $47.83 \pm 0.79$ & $48.83 \pm 0.43$ & NS \\
\hline Final LBW* $(g)$ & $\begin{array}{l}1650.42 \\
\pm 100.05\end{array}$ & $\begin{array}{c}1655.42 \\
\pm 55.22\end{array}$ & $\begin{array}{c}1616.95 \\
\pm 75.39\end{array}$ & $\begin{array}{c}1747.84 \\
\pm 32.35\end{array}$ & $\begin{array}{c}1686.04 \\
\pm 49.98\end{array}$ & $\begin{array}{c}1792.38 \\
\pm 22.93\end{array}$ & NS \\
\hline $\mathrm{DWG}^{\#}$ (g/ day) & $48.59 \pm 3.01$ & $48.70 \pm 1.64$ & $47.54 \pm 2.28$ & $51.47 \pm 0.94$ & $49.64 \pm 1.49$ & $52.89 \pm 0.70$ & NS \\
\hline $\operatorname{DFC}^{\ddagger}$ (g/ day) & $74.91 \pm 6.19$ & $72.94 \pm 2.96$ & $75.57 \pm 2.31$ & $79.86 \pm 3.16$ & $77.62 \pm 1.35$ & $82.05 \pm 1.18$ & NS \\
\hline $\mathrm{FCR}^{\$}$ (g feed/g gain) & $1.53 \pm 0.05$ & $1.50 \pm 0.08$ & $1.59 \pm 0.05$ & $1.55 \pm 0.08$ & $1.56 \pm 0.03$ & $1.55 \pm 0.04$ & NS \\
\hline
\end{tabular}

Sig.: Significance, NS: Non-Significant, "LBW: Live Body Weight, ${ }^{\#}$ DWG: Daily Weight Gain, ${ }^{*}$ DFC:

Daily Feed Consumption, ${ }^{\$}$ FCR: Feed Conversion Ratio. 
Table (3): Effect of dietary treatments on production efficiency (1-33 days of age).

\begin{tabular}{|l|c|c|c|c|c|c|c|}
\hline \multirow{2}{*}{ Parameters } & \multicolumn{7}{|c|}{ Dietary Treatments } \\
\cline { 2 - 8 } & $\mathbf{1}$ & $\mathbf{2}$ & $\mathbf{3}$ & $\mathbf{4}$ & $\mathbf{5}$ & $\mathbf{6}$ & Sig. \\
\hline RGR $^{*}$ & $188.89 \pm 0.60$ & $188.69 \pm 0.17$ & $188.42 \pm 0.54$ & $189.05 \pm 0.04$ & $188.95 \pm 0.18$ & $189.39 \pm 0.22$ & $\mathrm{NS}$ \\
$\mathrm{PI}^{\#}$ & $107.39 \pm 6.90$ & $111.21 \pm 8.86$ & $101.99 \pm 8.04$ & $113.23 \pm 7.22$ & $107.92 \pm 5.24$ & $115.82 \pm 4.35$ & $\mathrm{NS}$ \\
$\mathrm{PEF}^{¥}$ & $306.85 \pm 19.72$ & $317.75 \pm 25.33$ & $291.41 \pm 22.99$ & $323.52 \pm 20.66$ & $308.33 \pm 14.98$ & $330.91 \pm 12.44$ & $\mathrm{NS}$ \\
$\mathrm{PCR}^{\epsilon}$ & $0.30 \pm 0.01$ & $0.30 \pm 0.01$ & $0.32 \pm 0.01$ & $0.32 \pm 0.02$ & $0.31 \pm 0.01$ & $0.31 \pm 0.01$ & $\mathrm{NS}$ \\
$\mathrm{ECR}^{\$}$ & $45.40 \pm 1.42$ & $44.82 \pm 2.69$ & $47.80 \pm 1.67$ & $47.58 \pm 3.26$ & $46.95 \pm 1.16$ & $45.90 \pm 1.27$ & $\mathrm{NS}$ \\
\hline
\end{tabular}

Sig.: Significance, NS: Non-Significant; ${ }^{*}$ RGR: Relative Growth Rate, Brody (1945); "PI: Performance Index, North (1981); ${ }^{¥}$ PEF: Production Efficiency Factor, Emmert (2000); ${ }^{6} \mathrm{PCR}$ : Protein Conversion Ratio (g protein/ g gain); ${ }^{\$}$ ECR: Energy Conversion Ratio (1000 Kcal/ g gain).

Table (4):Effect of dietary treatments on some of carcass characteristics, 33 days.

\begin{tabular}{|l|c|c|c|c|c|c|c|}
\hline \multirow{2}{*}{\multicolumn{1}{|c|}{ Items (\%) }} & \multicolumn{7}{c|}{ Dietary Treatments } \\
\cline { 2 - 8 } & $\mathbf{1}$ & $\mathbf{2}$ & $\mathbf{3}$ & $\mathbf{4}$ & $\mathbf{5}$ & $\mathbf{6}$ & Sig. \\
\hline Dressed Carcass & $70.67 \pm 1.74$ & $70.58 \pm 1.68$ & $68.99 \pm 0.69$ & $71.81 \pm 0.92$ & $69.51 \pm 0.55$ & $74.15 \pm 1.58$ & NS \\
Abdominal Fat & $1.43 \pm 0.18$ & $1.65 \pm 0.12$ & $1.61 \pm 0.22$ & $1.66 \pm 0.12$ & $1.88 \pm 0.39$ & $1.82 \pm 0.21$ & NS \\
Giblets $^{*}$ & $3.58 \pm 0.30$ & $4.15 \pm 0.03$ & $4.08 \pm 0.09$ & $5.16 \pm 0.72$ & $4.50 \pm 0.30$ & $3.99 \pm 0.09$ & NS \\
Total Edible Parts $^{\#}$ & $74.26 \pm 1.45$ & $74.73 \pm 1.68$ & $73.08 \pm 0.60$ & $76.98 \pm 1.65$ & $74.01 \pm 0.26$ & $78.14 \pm 1.61$ & NS \\
\hline
\end{tabular}

Sig.: Significance, NS: Non-Significant, ${ }^{*}$ Giblets = Liver + Gizzard + Heart, ${ }^{\text {\#T}}$ Total Edible Parts = Dressed Carcass + Giblets

Table (5): Effect of dietary treatments on some economic traits.

\begin{tabular}{|c|c|c|c|c|c|c|}
\hline \multirow{2}{*}{ Items } & \multicolumn{6}{|c|}{ Dietary Treatments } \\
\hline & 1 & 2 & 3 & 4 & 5 & 6 \\
\hline Total Feed Cost ${ }^{\$}(\mathrm{LE})$ & 17.25 & 16.81 & 17.51 & 18.39 & 17.88 & 19.02 \\
\hline Total Production Cost ${ }^{\ddagger}$ (LE) & 30.25 & 29.81 & 30.51 & 31.39 & 30.88 & 32.02 \\
\hline Total Return" (LE) & 41.26 & $\varepsilon 1 . \Gamma$ & $\varepsilon \cdot . \varepsilon r$ & $\varepsilon r .79$ & $\varepsilon r .10$ & $\varepsilon \varepsilon . \wedge 7$ \\
\hline Net Return (LE) & 11.01 & 11.57 & 9.91 & 12.30 & 11.27 & 12.84 \\
\hline Economic Efficiency & 36.27 & 39.01 & 32.41 & 39.40 & 36.45 & 40.14 \\
\hline Relative Economic Efficiency ${ }^{d}$ & 100.00 & 107.54 & 89.36 & 108.61 & 100.49 & 110.65 \\
\hline
\end{tabular}

${ }^{\$}$ Feed cost includes processing costs; ${ }^{*}$ Total production cost $=[$ feed cost + price of one-day-old live chick $(8$ LE) + incidental costs $(5 \mathrm{LE})]$; ${ }^{\#}$ Total return is calculated according to local price of Kg sold live birds which was $\mathrm{r}^{\circ} .00 \mathrm{LE}$;

${ }^{x}$ Relative economic efficiency is determined assuming that relative economic efficiency of control (T1) group equals 100. 


\section{REFERENCES}

Abadi, M.H.M.G., H. Moravej, M. Shivazad, M.A. Karimi Torshizi, and W.K. Kim 2019a. Effects of feed form and particle size, and pellet binder on performance, digestive tract parameters, intestinal morphology, and cecal microflora populations in broilers. Poult. Sci. 98:1432-1440.

Abadi, M.H.M.G., H. Moravej, M. Shivazad, M.A. Karimi Torshizi, and W.K. Kim 2019b. Effect of different types and levels of fat addition and pellet binders on physical pellet quality of broiler feeds. Poult. Sci. 98:4745-4754.

Abdollahi, M.R., V. Ravindran, and B. Svihus2013. Pelleting of broiler diets: an overview with emphasis on pellet quality and nutritional value. Anim. Feed Sci. Technol. 179: 1-23.

Acar, N., E.T. Moran Jr., W.H. Revington, and S.F. Bilgili 1991. Effect of improved pellet quality using a calcium lignosulfonate binder on performance and carcass yield of broilers reared under different marketing schemes. Poult. Sci. 70: 1339-1344.

Aguzey, H.A., Z. Gao, W. Haohao, and C. Guilan 2018. Influence of feed form and particle size on gizzard, intestinal morphology and microbiota composition of broiler chicken. Poult. Fish Wildlife Sci., 6: 196

Baurhoo, B., C.A. Ruiz-Feria, and X. Zhao 2008. Purified lignin: Nutritional and health impacts on farm animals-A review. Anim. Feed Sci. Technol., 144: 175-184.

Behnke, K.C. 1996. Feed manufacturing technology: Current issues and challenges. Anim. Feed Sci. Technol. 62: 49-57.

Behnke, K.C. and R.S. Beyer 2002. Effect of feed processing on broiler performance. viii international seminar on poultry production and pathology. Santiago, Chile.

Brody, S. 1945.Bioenergetics and growth; with special reference to the efficiency complex in domestic animals. Reinhold.

Cecilia, M., F. Toledo, and P. M. Kuznesof 2008. Calcium lignosulfonate chemical and technical assessment. Pages $1-8$ in 69th JECFA, Rome, Italy

Cerrate, S., Z. Wang, C. Coto, F. Yan, and P.W. Waldroup 2008. Effect of pellet diameter in broiler prestarter diets on subsequent performance. Int. J. Poult. Sci., 7: 1138-1146.

Corey, A.M., K.G.S. Wamsley, T.S. Winowiski, and J.S. Moritz 2014. Effects of calcium lignosulfonate, mixeradded fat, and feed form on feed manufacture and broiler performance1. J. Appl. Poult. Res., 23: 418-428.

Cutlip, S.E., J.M. Hott, N.P. Buchanan, A.L. Rack, J.D.Latshaw, and J.S. Moritz 2008. The effect of steamconditioning practices on pellet quality and growing broiler nutritional value. J. Appl. Poult. Res. 17: 249-261.

Duncan, D.B. 1955. Multiple range and Multiple F tests. Biometrics, 11: 1-42.

Emmert, J. 2000. Efficiency of phase feeding in broilers. Proceeding, California Animal Nutrition Conference. Fresno California, USA.

Engberg, R.M., M.S. Hedemann, and B.B. Jensen 2002. The influence of grinding and pelleting of feed on the microbial composition and activity in the digestive tract of broiler chickens. Br. Poult. Sci., 43: 569-579.

Glover B.G., K.L. Foltz, I. Holásková, and J.S. Moritz 2016. Effects of modest improvements in pellet quality and experiment pen size on broiler chicken performance 2016 J. Appl. Poult. Res. 25:21-28

Hetland, H., B. Svihus, and V. Olaisen 2002. Effect of feeding whole cereals on performance, starch digestibility and 
duodenal particle size distribution in broiler chickens. Br. Poult. Sci. 43: 416423.

Jahan, M.S., M. Asaduzzaman, and A.K. Sarkar 2006. Performance of broiler fed on mash, pellet and crumble. Int. J. Poult. Sci., 5: 265-270.

Jensen, L.S., L.H. Merrill, C.V. Reddy, and J. McGinnis 1962. Observations on eating patterns and rate of food passage of birds fed pelleted and unpelleted diets. Poult. Sci. 41:1414-1419.

Maiorka, A., F. Dahlke, A.M. Penz, and A.M. Kessler 2005. Diets formulated on total or digestible amino acid basis with different energy levels and physical form on broiler performance. Brazilian $\mathrm{J}$. Poult. Sci., 7: 47-50.

McKinney, L.J., and R.G. Teeter 2004. Predicting effective caloric value of nonnutritive factors: I. Pellet quality and ii. prediction of consequential formulation dead zones. J. Poult Sci.: 85:1165-1174.

Mingbin,L.V.,Y.Lei,W.Zhengguo,A.Sha, W.Miaomiao,and L.V.Zunzhou2015. Effects of feed form and feed particle size on growth performance, carcass characteristics and digestive tract development of broilers. Anim. Nutr.,1:252-256

Moran, E.T. 1989. Effect of pellet quality on the performance of meat birds. In: Recent Advances in Animal Nutrition, Butterworths, London, pp:87-108.

Moritz, J., K.J. Wilson, K.R. Cramer, R.S. Beyer, L.J. McKinney, W.B. Cavalcanti, and X. Mo 2002. Effect of formulation density, moisture and surfactant of feed manufacturing, pellet quality and broiler performance. J. Appl. Poult. Res. 11:155-163.

North, M.O. 1981. Commercial chicken. Production Annual, 2nd Edition, Av., Publishing Company I.N.C., West Post. Connecticut, USA.
NRC 1994. National Research Council. Nutrient Requirements of Poultry 9th Rev. Ed. Composition of poultry feedstuffs. National Academy Press, Washington, DC, USA. p.p. 61-75.

Parsons, A.S., N.P. Buchanan, K.P. Blemings, M.E. Wilson, and J.S. Moritz 2006. Effect of corn particle size and pellet texture on broiler performance in the growing phase. J. Appl. Poult. Res., 15(2): 245-255,

Salari, S., H. Kermanshahi, and H. Nasiri Moghaddam 2006.Effect of sodium bentonite and comparison of pellet vs mash on performance of broiler chickens. Int. J. Poult. Sci., 5: 31-34.

Saleh, E.A., S.E. Watkins, A.L. Waldroup, and P.W. Waldroup 2004. Effects of dietary nutrient density on performance and carcass quality of male broilers grown for further processing. Int. J. Poult. Sci., 3: 1-10.

SAS 2004. SAS/STAT ® 9.1 User's Guide. Cary, NC: SAS Institute Inc.

Skinner-Noble, D.O., L.J. McKinney, and R.G. Teeter 2005.Predicting effective caloric value of nonnutritive factors: III. Feed form affects broiler performance by modifying behavior patterns. Poult. Sci., 84: 403-411.

Svihus, B. 2014. Function of the digestive system. J. Appl. Poult. Res. 23:306-314.

Taylor, R.D., and G.P. Jones 2004. The incorporation of whole grain into pelleted broiler chicken diets. II. Gastrointestinal and digesta characteristics. Br. Poult. Sci. 45: 237246. 


\title{
الملخص العربي
}

تأثير رابط المصبعات على الأداء الإتتاجي لاجاج التسمين وإقتصاديات تصنيع الأعلاف

\author{
مروان عبدالعزيز محمود عبدالعزيز

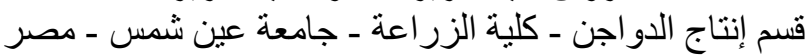

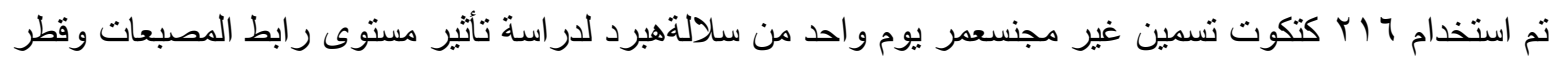

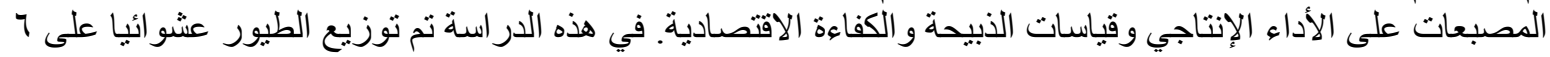

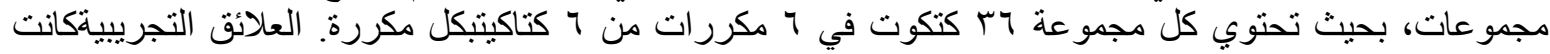

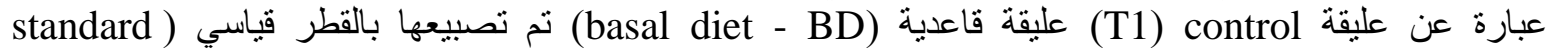

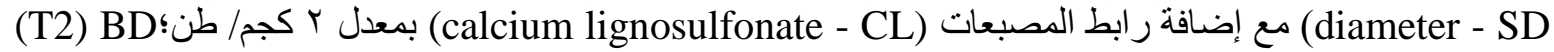

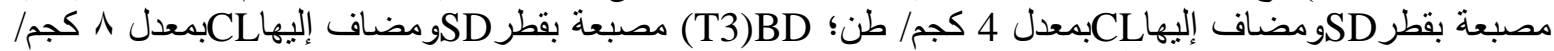

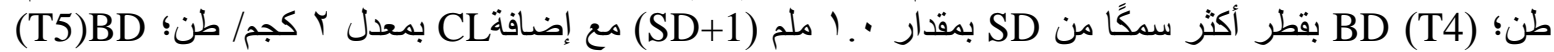

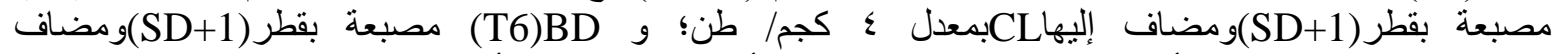

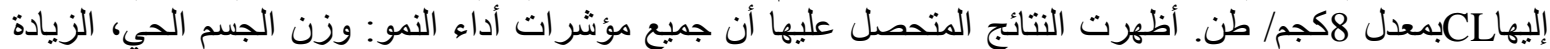

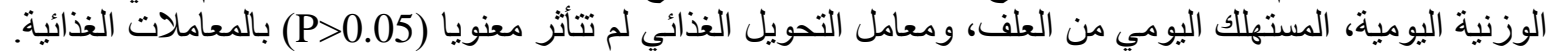

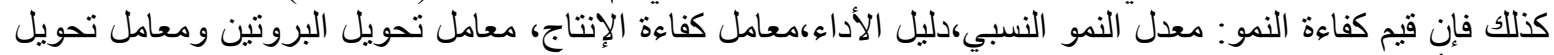

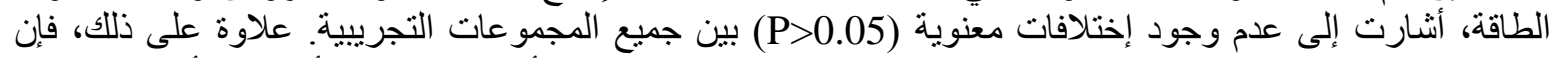

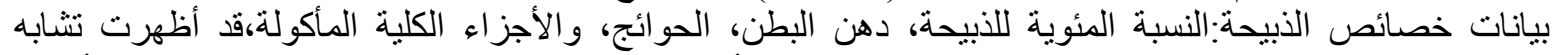

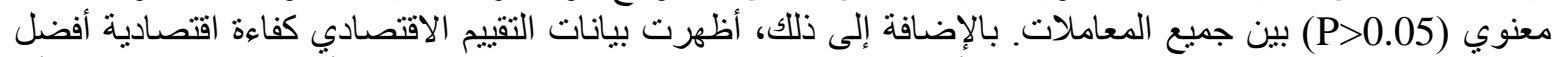

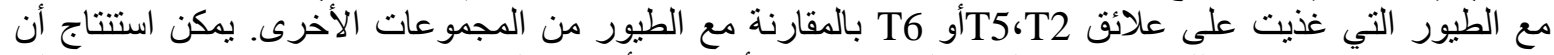

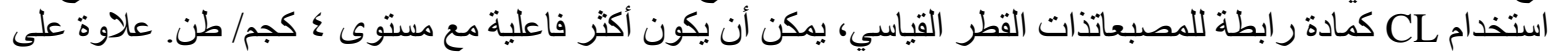

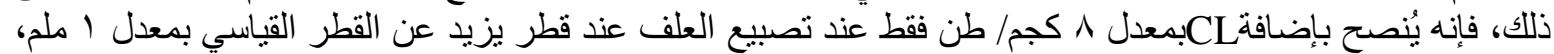
حيث استطاعت العلائق بتلك المو اصفات أن تدعم الأداء الإنتاجي وخصائص الذبيح الذبحة بشكل إيجابي. 